\title{
Accessibility Study of Touch and Gesture Interaction with Seniors
}

\author{
André Luiz Abrahão, Amanda Cavalcanti, Luis Lucas Pereira, Licínio Gomes Roque \\ Departament of Informatics Engineering \\ University of Coimbra \\ Coimbra, Portugal
}

\begin{abstract}
At a time when there is the widespread use of new applications with touch and gesture interfaces, it is important to question whether these represent a positive differential to the accessibility of the senior population or whether they are yet another excluding info artifact. The purpose of this article is to present preliminary results for the potential and limitations of touch and gesture interfaces, through the proposal of usability heuristics for this audience, which subsequently will be proven, rebutted and calibrated by a prototype game for tablets with features based on cognitive and motor rehabilitation. The intention is that the game prototype based on the activities of harvesting, collecting of bunches of ripe grapes, carrying baskets and crushing grapes to make wine prove or refute the proposed heuristics.
\end{abstract}

Keywords-senior users; multitouch; heuristics, game prototype

\section{INTRODUCTION}

The ageing of society is an imminent reality, due to the improvement of public policies and the increase of multidisciplinary research through new medicines or implementation of assistive technologies. One of the populations that show considerable demographic growth is the senior audience. Statistics of 2011 [27] show that they can go from the current 650 million to over 2 billion in the next 20 years. In Brazil, IBGE data [16] show that this growth is associated with the progressive decline of birth and mortality rates, resulting from improved nutritional, employment, sanitation and housing conditions, as well as new discoveries in medicine such as antibiotics and vaccines. In Portugal, for example, the proportion of elderly people was $19 \%$ in 2011 . This figure contrasts with the $8 \%$ recorded in 1960 and $16 \%$ in the preceding decade. Portugal, according to the 2011 Census [7], has more elderly than young people. In view of this situation, experts from various technological areas, including computer science, telecommunications and engineering have sought means to remedy the problems faced by the elderly, mainly to ease the interaction with these new technologies. After all, according to Kachar [21], "Computers and information technologies offer the potential to improve the quality of life of the elderly, providing them information and useful services to their daily life".

However, this is not a simple task because of the fear of the public of using electronic devices. The elderly - opposed to the generation born in the universe of icons and Internet - have revealed serious difficulties in understanding metaphoric language imposed by the electronic media. Everyday actions like handling menus for televisions, answering a mobile phone or operating ATMs become difficult tasks to be carried out, due to physiologic and cognitive challenges that define human ageing.

Coordination skills with the mouse, for example, are among the most obvious difficulties observed in the elderly's interaction with Graphical User Interfaces (GUI). Tasks that involve pressing a target or a double-click to trigger an action are challenging for users with problems of accuracy.

It is assumed that the elimination of traditional input mechanisms, such as mice, keyboards, or joysticks, would provide a more direct, natural and intuitive interaction with a computing device. However, this becomes a controversial convention, when we relate it with elderly people. At the same time that there are studies that consider the potential of these devices, there are others that assess them as just one more excluding info artifact.

Multitouch interfaces, the currently most common example of TUI, may be more effective in reducing cognitive load and fostering a better interaction experience. However, they can be inadequate for tasks that involve precision, in cases of accidental activation caused by Parkinson's or arthritis. The complexity of gestures and the minimum amount of space required for performing them may increase this difficulty.

This dichotomy raises hypotheses about the potentials and limitations of this technology for the elderly population; this is relevant because of the recent tendency for interactive projects that include the concept of universal design. This research will focus on the creation of usability heuristics for applications based on multitouch interfaces according to the physiological characteristics of senior user. Once these heuristics are proven, they will be rebutted and calibrated by a prototype for a multitouch interactive game with a rehabilitative character.

It is expected that this research contributes as a basis for other related studies and serves as a reference for the development of multi-touch applications that suit the needs of the elderly, empowering them to make use of these for the improvement of their quality of life and inclusion in society. 


\section{A. Physiological aspects of third age}

Psycho biological features of old age, involving questions about visual, hearing, motor, and cognitive acuity, have been investigated. Visual acuity problems cause the loss of autonomy of the elderly in the environment where they live, as they tend to reduce the frequency and intensity of daily activities, such as reading or driving, becoming more dependent of others.

Kachar [21] reports that from the age of twenty-five people start to feel difficulty in seeing at night, reading and identifying nearby objects. There is also a decrease of color and light perception. Pak [29] emphasizes that fact when he says that the night vision of the elderly resembles the permanent use of sunglasses. Papaléo [28] shows some diseases common to the senior citizens: Presbyopia, for instance, is characterized by the accommodation of the lens, i.e. there is a loss of elasticity of this component of the human eye, making it inflexible and unable to distinguish shapes and colors. Another problem related to the vision of the elderly is cataracts, characterized by a gradual opacity of the lens of the eye, resulting in a hazy vision highly susceptible to reflected light. Glaucoma, a neuropathy in which the intraocular pressure is one of the various elements related to its pathogenesis, macular degeneration, an injury or decomposition of the macula, and diabetic retinopathy, the ocular manifestation of diabetes mellitus, are also related to loss of visual acuity.

The mentioned factors must be considered in the development of interactive applications, as the elderly may have difficulties in decoding information represented by visual signs of the interface such as typography, colors, pictures and instructional elements. In the design of interactive applications auditory aspects should be considered. Filho [10] states that the ear canal compensates for the visual impairment reinforcing the information captured by the sight. When selecting hearing signals the purpose of the sound and the hearing capabilities of the user should be considered, in addition to the conditions of the environment where the interaction will be held. Ideally, the sound quality of these application types should be balanced, considering that both low and extremely high sounds can lead to unsatisfactory experiences for the user. This balance is necessary because - like in vision - hearing aspects also suffer the influence of ageing and become unstable. Grandjean [14] shows that in men, for example, hearing losses are greatest in the high frequency range. In general, it is expected an average hearing loss of $3,000 \mathrm{~Hz}$ at the age of $50(10 \mathrm{~dB}), 60$ years $(25 \mathrm{~dB})$ and 70 years $(35 \mathrm{~dB})$.

Motor control refers to the accuracy and response time of human movement. Degenerative diseases, such as Parkinson's or arthritis, are related to the difficulty raised by these conditions with the triggering of buttons or dealing with precision mechanisms. Pak and Mclaughlin [29] say that arthritis is related to pain, swelling and stiffness of the joints, resulting in the possibility of bone malformations, which may cause difficulties of direct manual interaction with screens. The same author emphasizes this by stating that "in general, users with arthritis will have difficulty with tasks that require fluid finger movements, or specific pressure: small buttons are bad choices for users with this type of disease".

In relation to the cognitive aspect, there is a natural decline in the ability to acquire and recall information. Kachar [21] shows that there is a gradual increase in complaints of memory loss with the advancement of age: less than $10 \%$ below the age of 50 to more than $42 \%$ in the age of 80 . "This characteristic forgetfulness of the third age is defined by Iida [18] as the inability to retrieve stored information." Cybis [9] extends this concept, stating that oblivion is raised by the increase in number and similarity of declarative knowledge (concepts), and by the mismatch between the encoding and retrieval contexts of procedural knowledge. Having criteria for organizing, categorizing, differentiating and discriminating information is essential for good interaction of the elderly with interactive systems. It is essential that the memory of users is not overloaded with irrelevant procedures. Consistency of elements, coherent encodings, volume segregation and chromatic aspects are indispensable, as they may contribute to the proper use of systems.

\section{B. Elderly and new technologies}

New technologies have invaded homes, businesses and society, becoming an increasingly vital need. However, despite this revolution in technological means, a large portion of the population is unable to follow this trend. There are heterogeneous user groups handling information systems. The young audience, for instance, learns to live with these new technologies from an early age, making computer handling something intuitive and common, as their curiosity provides a rapid learning. The elderly, on the other hand, are afraid of using computerized systems for believing they will mishandle the computer and damage it.

Some researchers, however, argue against this stereotype that 65 -year-old adults refuse to be aware of technological innovations. Pak [29] shows that more or less half of the elderly between 65 and 74 years are mobile phone subscribers and one third of those over 75 pay for this service. Tanaka [34] shows that in Japan bank lending services through interactive television are already a reality for the elderly public since 2004. A study carried out in 150 homes confirmed this technology has good possibilities, proved by a significant increase in the number of bank transaction.

Additionally, it is worth noting that the computerized procedures and their different media (audio, video and text) have become fundamental elements to support elderly rehabilitation. One of the possibilities is the use of games, not only for entertainment, but also for educational, social and therapeutic purposes. Commercial web services such as Lumosity aggregates games that exercise the cognitive aspect and rely on an audience of 20 million regular players who pay the equivalent to 10 dollars a month.

The use of tablets and smartphones is also a reality among this audience. Bhalla [3] shows that this acceptability is due to the ease of use of touch interfaces, because users can find information more easily with only a touch. Umemuro [38] reinforces this idea when he proves in his study that the anxiety level of users who use the screen as an input mechanism decreases in relation to those using the keyboard. 


\section{Specificities of use in tangible interfaces}

There has been an evolution in electronic means. There has been a paradigm break, as point-click technology is being substituted by interaction through gestures. The "removing" of traditional input mechanisms such as the mouse, keyboard or joystick provides a greater range of possibilities for system activation when using all the human body. Gestural interfaces can be categorized into touchscreen or free-form. Touchscreen interfaces require direct "touch" contact with the devices, while free form gestural interfaces are characterized by the use of the human body as an input device for interaction (e.g. Kinect).

One of the first approaches deals with a few requirements that must be considered in the development of gesture-based interfaces. Saffer [33] prioritizes some of these features; discoverability, the first, shows the importance of the evidence of affordances in interactive system. Affordance refers to one of several properties of an object that gives some indication of where and how it can be accessed. This concept was popularized by Norman [25], who criticizes [26] the inefficiency of gestural interfaces as he considers them to be retrogrades in relation to usability, saying "[...] Apple specifically recommends against the use of menus, the Android UI team takes the opposite position, even providing a dedicated menu key, though not activated. In addition, swipes and gestures cannot be readily incorporated into menus. Unfortunately, so far no one has figured out how to inform the user on the ways he can access the application".

Two other qualities proposed by Saffer [33] are reliability, based on the aspects of security and privacy to the user, and responsiveness, related to instant response time in up to 100 milliseconds. Every action performed by a human on a gestural interface, no matter how small, should be accompanied by some recognition of the action, whenever possible. The fourth quality refers to the appropriateness of this technology in relation to culture, location and context. Some gestures are offensive in some cultures. An "OK" gesture, quite common in North America and in almost all Western Europe, is regarded as offensive in Greece, Turkey and Russia, for instance. Complicated gestures, that involve sudden movements of the arms and legs or fingers, are unsuitable for the elderly or those who have some kind of physical disability.

Studies conducted by Saffer [33] and Jacko [19] suggest tangible interfaces have a number of advantages over traditional graphical interfaces. However, when it comes to the elderly, the subject divides opinions, because some issues related to motor features are inaccurate, in spite of relying heavily on intuition. Saffer [33] says that touchscreen devices need to be accessible to different users of all ages; therefore, simple gestures such as pushing buttons are suitable to the interactive context. It is, however, desirable to use simple and elegant gestures for solving complex tasks. The "ideal gesture" and proper use of multitouch interfaces are not always achieved, because there is the possibility of inherent feedback, the risk of inadvertent activation or difficulties with precision. As this is much more critical in the elderly, similar gestures for different actions should ideally not be developed, to prevent the users from accidentally firing other affordances. Stoessel et al [35] contributes to this discussion stating that the increased complexity of gestures and the reduction of the space allocated for their performance tend to generate errors during the interaction.

\section{GOALS AND METHODS}

The goal of the research is the composition of usability heuristics for applications based on multitouch interfaces according to the physiological characteristics of senior users. Subsequently, these heuristics will be evaluated by a prototype for a multi-touch interactive game with a rehabilitative character.

Research in the context of design is an analytical process and, according to Silva [34], it searches, through different areas of knowledge and other research methods, a basis for the creation of its own methodology. This new methodology will then generate a body of knowledge which, in turn, will lead to relevant theoretical construction for the solution of a specific problem.

The intent of this study was to propose a set of guidelines as a basis for future studies on the elderly, interaction and multitouch devices triad. To empirically study these relations we opted for the Design Research (DR) methodology, as it supports the production and study of artifacts through which theoretical constructs can be tried and tested. Hevner [15] has proposed the DR methodology can be structured in five stages: problem identification and awareness (awareness of problem); proposal of solutions to this problem (suggestion); prototyping (development of artifacts); evaluation; and statement of learning, which can be characterized as the phase of knowledge production.

In his studies, C. Rusu et al [5] propose four stages that support the production of new heuristics from existing ones that were inserted in the scope of the solution proposal. The first stage, called exploratory phase, is characterized by the collection of bibliographic material related to the main topics of research on heuristics. The second stage, heuristics synthesis, highlights the most important features of the information previously collected, in order to formalize key concepts associated with this research. The third stage, or correlational stage, was relevant to identify the characteristics that usability heuristics should have for specific applications, based on studies of traditional heuristics.

At the end of the problem identification and contextualization stage, the offer of solutions has been stipulated through an explanatory component to specify the proposed set of heuristics through a standardized model. Each new proposed heuristic was presented as follows: the most important references, a synthetic description, the nomenclature, and the definition.

After the proposal of the six heuristics, it was necessary to prove, refute and calibrate them by producing a prototype artifact through which we could collect evidence of the influence of the proposed heuristics in the design. This was done by creating a game for the iPad. This prototyping phase is the fourth step of the Design Research methodology. At this stage both low and high-fidelity prototypes were used. 
The low-fidelity or paper prototypes were run with five professionals who either worked with games or interface design to evaluate the elements that made the mechanics of the game. The method used in this stage of evaluation was the Design Walkthrough, which Preece et al [32] argues to be an alternative approach to heuristic evaluation, in order to predict the user's problems before carrying out tests on final artifacts. As the name suggests, there are tasks or usage scenarios with a low or high fidelity to identify future problems of use. Most of the techniques presented in Design Walkthrough don't involve end-users. The intention in this first phase of tests was: a) to explore the technical possibilities in terms of components and their arrangements in each screen; b) to verify the effectiveness of the conceptual aspects of the interface as metaphors and graphical structure and c) to seek contributions on aspects of prototype gameplay.

For the development of the interactive prototype, we also used Garret's user experience design method [13]. We opted for Garret because method focuses on variables associated with usability, navigability and information architecture. Once the prototype has been set by implementing the relevant heuristics to assess their applicability, we proceeded with an evaluation phase to assess the effectiveness of their application.

Later, with the evaluation parameters already listed, we opted for a high-fidelity prototype, programmed in the Corona SDK for iPads and Android tablets, in order to provide a more precise test and data collection for the proposed heuristics.

The post-prototyping step of the Design Research methodology, named evaluation, involved comparing the goals of a solution with the results obtained with the use of the interactive artifact. For this phase, we proposed the analysis of actions and behaviors of the elderly by means of interaction logs and records of the user's emotions through video analysis and application of task satisfaction questionnaires. The interpretation of interaction logs was based on the GoalQuestion-Metric (GQM) paradigm, an approach to effective measurement introduced by Basili [2]. The assessment of emotions was based on a set of ten emotional heuristics to identify the reactions of the elderly during the interaction with the game prototype. This comprises a comparison of the goals of a solution with the results obtained with the use of the artifact, the game prototype, in this case.

The last stage, or statement of learning, will be characterized by the dissemination of the knowledge acquired during the research. Highlighting the problem of heuristics for senior users and the way they were calibrated based on an interactive game prototype may be relevant for other researchers and practitioners in the field of interaction design, especially those interested in the proposal of new design heuristics.

\section{HEURISTICS PROPOSALS}

Following the methodological plan of activities, the first activity involved synthesizing a proposal of usability heuristics to use on design for multitouch platforms targeted at elderly users.

\section{A. Bimodal Feedback}

According to Cybis [9], feedback is an essential criterion for any interactive system. The quality and speed of response to the user's actions are essential to the success of their tasks performance. Preece et al [32] reinforce this idea by saying that the proper use of feedback can provide the required visibility for users' interaction.

This premise becomes more evident when we deal with the elderly. In this case, any kind of inappropriate or lengthy response of the system can generate frustration and fear, either due to the feeling of having performed an inadvertent task or having caused physical damage to the unit. Stoessel et al [35] support the assertion that older users have a special interest in security and protection during the interaction and are often afraid to get lost within a system or to damage it through improper use; this loss of feedback can be seen as particularly damaging among this group of users.

In relation to multitouch interaction, usually all systems provide some kind of feedback. However, as there is a natural decline of the senses at this age, it is assumed that unimodal feedback based on visual aspects is insufficient to meet the needs of senior users, being also necessary the stimulation of tactile and auditory senses. Pak and Mclaughlin [29] show that a feedback most suited to the elderly should involve auditory visual combined with haptic components. However, Caprani [6] found that the use of two components is sufficient to promote a good interaction. In our work the proof of concept will be held on an iPad, so the haptic variable will not be considered.

Pak and Mclaughlin [29] argue for special attention to be paid to the response time of the system in relation to senior users. A time response appropriate for the user interaction should be prioritized, because what is reasonable for the younger ones may be too short for older adults, due to deficit of perception and attention constraints. Ingram [17] stresses that this feedback should be intermittent in all stages of action when we deal with users, but cautiously so that it doesn't overload the system with too many visual and auditory stimuli. Regarding the quality of feedback in Natural User Interfaces (NUI) systems, Wigdor and Wixon [42] advise that in systems based on single touch, it should be developed a set of visual states (with transitions that would ensure minimal coverage of several errors by providing visual interactions) and unique transitions for each state by removing the ambiguities of unexpected behavior.

In this way it is proposed:

H1: The use of bimodal feedback (sight and hearing) with a response time suited to the specific needs of the senior user throughout the whole process of interaction with multitouch applications.

\section{B. Appropriate spacing and sizing}

According to Pak and Mclaughlin [29], degenerative diseases of the motor system - such as Parkinson's and arthritis - affect the interaction of the elderly with multitouch applications, especially when they demand precision or sensitivity to control them. For instance, juxtaposed buttons are a bad choice for elderly people with arthritis, since they 
cannot conduct fluid movements with their fingers. Additionally, gesture complexity decreases users' accuracy in a reduced space of interaction.

To avoid these unsuitable designs, Jin [17] considers that minimum size for buttons or icons should be of $19.05 \mathrm{~mm}^{2}$, with spacing from 6.35 to $12.7 \mathrm{~mm}$. These settings should especially be considered if the user's dexterity is critical, and the application should only demand simple interaction movements (tap, wave, click, press). Saffer [33] mentions another uncertain dimension parameter for users with motor impairments: "Although there still aren't guidelines to make the interaction more accessible, it is important to consider larger targets than usual, about $150 \%$ or $1.5 \mathrm{~cm}$ more than the standard". These parameters can be compared during the proving of concept. Wigdor and Wixon [42] consider that in minor touch areas, where users use the hands or thumbs to make a selection, a target with $9 \mathrm{~mm}$ is sufficient.

The spacing between elements is another factor that undermines accuracy. An example is the QWERTY keyboards that have minimum spacing, which hinder people with thicker fingers, especially the obese ones. Stoessel et al [32] hypothesize that the growing complexity of gestures and the reduction of space between the targets contribute to the decrease of accuracy, especially among older users.

Pak and Mclaughlin [29] consider that the Gestalt theory can contribute to the design of adequate spacing between elements, especially when proximity and similarity laws- used to create visual categories that are harmonious and understandable- are applied in the display.

Summing up, the proposed guideline is:

H2: Development of touch targets and spacing appropriated to the motor deficiencies or characteristic of the senior users.

\section{Graphics and interaction consistency}

The heuristic criterion of consistency is perhaps one of the most relevant for the elderly population. This is because when they interact with sign or graphic standardization, they create mental models that will later be used with other elements of the interface. One of the benefits of consistent interfaces is that they are easier to learn and use. According to Preece et al [28], users only learn a single mode of operation applicable to all objects.

Chen [6] shows that color, positions or functions alternation or changes affect older adults. These effects include performance and learning time. The use of the criterion of consistency in a single application reduces the user's memory load and the risk of errors.

The variation of screen patterns can reduce the performance of the senior user because the gesture patterns thought at the beginning of the interaction might be diverted. This causes the elevation of cognitive and motor load in the fulfillment of tasks. Stoessel et al [35] state that the number of unnecessary screen changes is an estimate of navigation inefficiency. Ideally, the gestures made by users should be consistent throughout the interface, being perfectly simple and not complex.

\section{Guideline proposed:}

H3: Consistency and stability of graphic elements and their composition in the touch interface, in order to preserve the patterns of gestures across the space of possible interactions with the application.

\section{Appropriate metaphors}

Seniors are often "afraid" or discouraged to use computerized means, because, differently from the Internet generation, their understanding of interface's graphics is complex and far from the actual representations already assimilated by more familiarized users.

Kachar [21] exemplifies this by noting that older users identify the icons relying on their own references and contexts. The floppy disk in the toolbar of Microsoft Word is identified as a television and the printer icon as a toaster. Preece et al [32] note that emulating real-world activities in the interface can be a powerful design strategy, since the new incorporated functionality extends or supports user's tasks in ways that are not possible in the physical world.

In this case, metaphors are essential to provide users with cognitive shortcuts through pre-existing templates in memory when they learn to cope with new systems, according to Yang [40]. The application of this concept, according to Yousef [41], minimizes the cognitive effort of the elderly during the use of any system, thus offsetting some limitations. In this way, the use of interface metaphors based on pre-existing mental models provides users with a reduced cognitive load and the consequent confidence and motivation to explore a new system. Additionally, as these are tangible interfaces, it is necessary that the gesture input matches the real context, making the interaction as natural and intuitive as possible.

Moggdrige [24] suggests the development of a standardized system of sign language related to manageable elements of the world, with controls that are intuitive and easy to remember.

In this way it is proposed:

H4: To develop patterns of gestures and metaphorbased interface elements which are consistent with the cultural identity of the elderly.

\section{E. Interfaces consistent with visual acuity}

Visual acuity problems lead to the loss of autonomy of the elderly in the environment where they live. As they fail to perform or have to reduce daily activities, such as reading or driving, they become dependent on other people to help them.

According to Kachar [21], there are several changes in vision that evolve naturally over the years. From the age of thirty-five people begin to have difficulties to read and to identify nearby objects. There is also a decrease on light and color perception, as well as a difficulty in seeing at night.

Pak and Mclaughlin [29] report that color perception alters with the normal wear and tear of the eye "lenses", which change its transparent appearance to a yellowish one. This provides a greater absorption of blue light, giving the perception that the colors are less blue and more yellow, so it 
is more difficult to distinguish a shade of blue from the other. In several cases, the differentiation between red and purple tones becomes more difficult as well.

In relation to the perception of the visual elements of the interface, it is also natural that there are difficulties in perceiving icons in computer terminals, since it takes longer to understand and select information when the icons are more abstract or very similar, and this is related to the loss of visual acuity.

Cybis [9] concludes that readability is one of the most important interface ergonomic criteria for the elderly or people with vision problems. In this case, there must be some concern about the readability of graphical elements; factors such as character brightness, contrast between background and main information may compromise the immediate perception of information.

The issue of brightness intensity in screens, according to Pak [29], should also be addressed since the process of adaptation to darkness occurs more slowly for older adults. A solution may be to avoid rapid changes in the screen glow and provide quickly accessible controls to brightness to allow the user to choose a comfortable level.

Since much of the informational aspect is related to the use of texts, questions about the proper use of types must be considered. Phiriyapokanon [31] states that older people can benefit from the use of sans-serif types of size 12-14 point, normal view (72 dpi), short line lengths and left-justified text.

In this way it is recommended:

H5: Interfaces focused on the aspect of readability, which are consistent with the elderly' visual acuity needs.

\section{F. Amount of affordances / points of interaction}

Another issue suggests limiting the number of screen interaction elements so that there is a decrease in cognitive load. According to Kachar [21], in addition to the motor coordination problem, the cognitive deficit interferes with the performance of the users, because they do not organize information into categories and do not form visual images as easily. This impairment makes users' memorization difficult, decreasing their ability to manipulate and organize information on a short-term basis.

In this way, it is recommended to only use information relevant to the application context, because there is a possibility that a crowded screen hinders the process of memorization of the elderly and thus the assertiveness of the interaction.

Cybis [9] points out that the user's performance is decreased when the information density is too high or too low. This information retention capacity relates to short term memory, whose average retention capacity is commonly explained in Cognitive Theory to be around seven independent units [18].

Depending on the circumstances and the degree of attention, this ability can vary between five and nine concurrent units. This means that there is a $100 \%$ hit when remembering up to five units related to one other, and from there, errors begin to increase rapidly.

Thus we proposed:

H6: To limit the number of interaction elements and affordances in specific multitouch screens, so that there is a decrease in cognitive load by the senior user.

\section{STATEMENT OF APPLICABILITY OF PROPOSED HEURISTICS}

One of the intentions for the development of the game prototype is that it is not just an instrument for applicability analysis and calibration of heuristics but also an artifact that refers to cultural aspects and the daily life of the elderly, so that they do not feel taunted during the interaction. Design as an interdisciplinary area can contribute to this purpose concatenating technological, visual and anthropological aspects in search of a product that suits the specificities of this public.

Therefore, before the development of the application's interface it was necessary to develop a concept for the game prototype. One of the steps was to seek for a theme in the Iberian culture related to a movement or popular festivity whose essence involved the friendship between different generations. In this context Christmas, New Year, Easter, Magusto (chestnut roast), employers' parties, Weddings, Baptisms, Communions were all referred; however, the choice was the Grape Harvest.

The Grape Harvest is the harvest of bunches of grapes intended for the production of wine, when those reach the right degree of ripening. This event is usually characterized by the arrival of workers from neighboring places to contribute to the harvest. In this way, it starts one of the most characteristic moments of European ethnography.

At the time of the Grape Harvest, festivals are organized in different lands or regions, in a historic tradition where generations of families get together for wine production. This festive moment attracts tourists, for instance, to the region of Douro, in Portugal, the oldest demarcated wine region in the world. According to Pinto [30], this kind of family festivities has a special meaning for the elderly, as it gives the family an opportunity for personal, familiar, social and moral growth, creating situations favorable to educational, social and therapeutic action. Activities idealized for the game prototype were inspired on common harvest activities. This ideation involved making sure these game activities would be an instrument for the calibration of the proposed heuristics and for the stimulation of the synesthetic, cognitive and motor senses, through multitouch interaction.

The first activity we proposed was the collection of ripe bunches of wine growers. The challenge was to identify small color differentiations (affordances) among the green plantation that indicate the location of shrubs with bunches of ripe grapes ready for harvesting. 


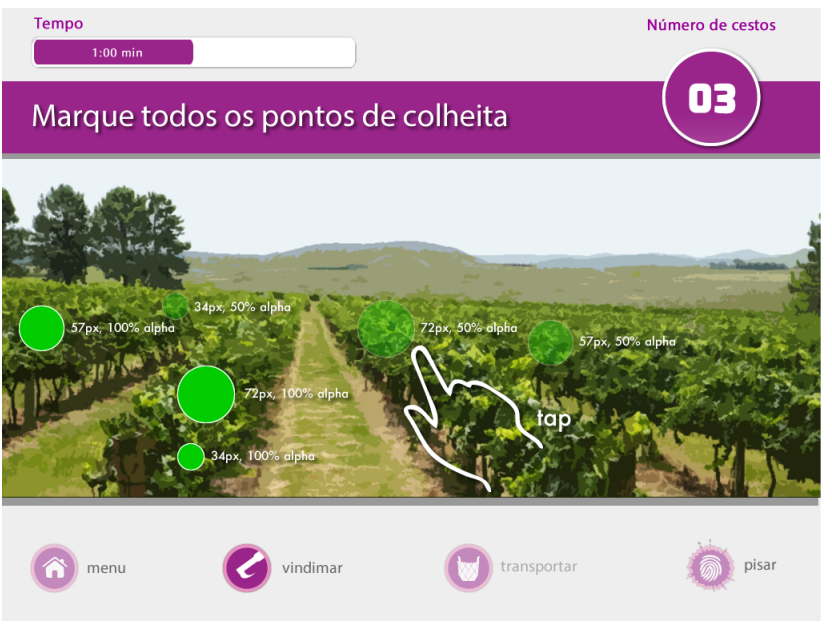

Fig. 1. Targets taping and sizing activity

This part of the prototype enables measuring the effectiveness of two heuristics: appropriate dimensioning and spacing and interfaces consistent with visual acuity. The elderly have difficulty in distinguishing chromatic tones, thus, the first task is to identify and "pinpoint" visual cues (affordances) along the extensive green shrubs that indicate the location of harvesting sites. These indication points can change its positioning, color and size. Alternately, varying the size and coloring of affordances can highlight or disguise the target for senior users.

When the user "taps" each affordance, the game shows a pop-up screen that represents a shrub, comprised of bunches of grapes, inserted in a tangle of leaves. This will be the basis for another activity that combines visual acuity and motor skill.

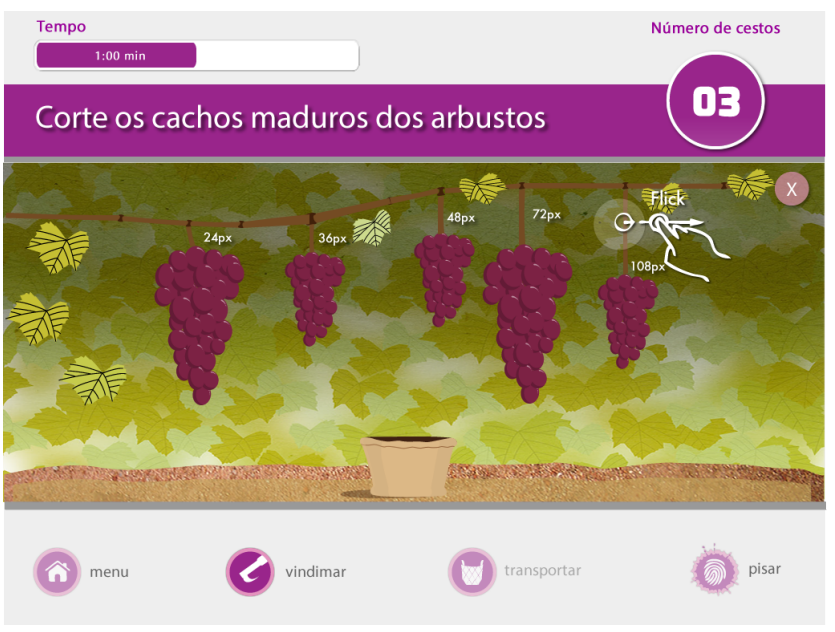

Fig. 2. Visual acuity motor skills exercised through the prototype

This activity intends to further promote the exercise of visual acuity. Appropriate dimensioning and spacing heuristics will be exercised through the task of separating bunches from the bushes through the "flick" gesture, as shown in Figure 3. The thickness of the "cable" and its distance from the bush can be used to calibrate the proposed heuristic.

The second prototype activity is to lead the workers with the grape baskets to the trucks, with a continuous drag motion. The challenge of this game stage is to take their baskets, duly identified by colors, to the vehicles with the same color. The player cannot touch the edges of the tracks, otherwise the racks are lost. This game activity exercises motor acuity.

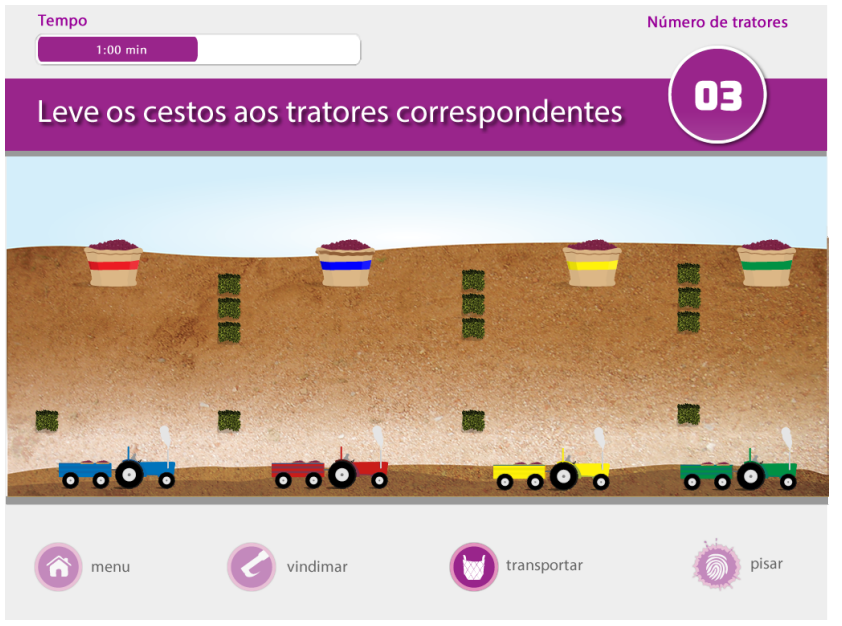

Fig. 3. Exercises scuity motor activities by drag

This activity intends demonstrates the heuristics of graphic and interactive consistency. By definition, the elderly prefer templates; a drop in the learning curve may result in errors and, consequently, in the abandonment of the system. The purpose is to study senior user's touch interaction behavior in relation to the placement and color alternation of the prototype graphics on the screen.

The last activity, called "grape stomping", is related to one of the main problems faced by the elderly audience: difficulties in short term memory management. The intention is to use some strategies to mitigate this problem, such as information consistency, pattern repetitions and hearing assistance in addition to visual information. This activity includes "filling" the wooden barrels of wine presses with a minimum percentage of grape juice. The challenge will be to "stomp" each of the grape berries that appear on the screen in a sequential numerical order.

The berries are shown for 5 seconds so that the player memorizes the sequence in which they appear. In an ascending order of difficulty, the berries will appear in greater numbers. To study the effect of multisensory stimulation, a combination of color and relative size of berries can be used to help perceive the order. 


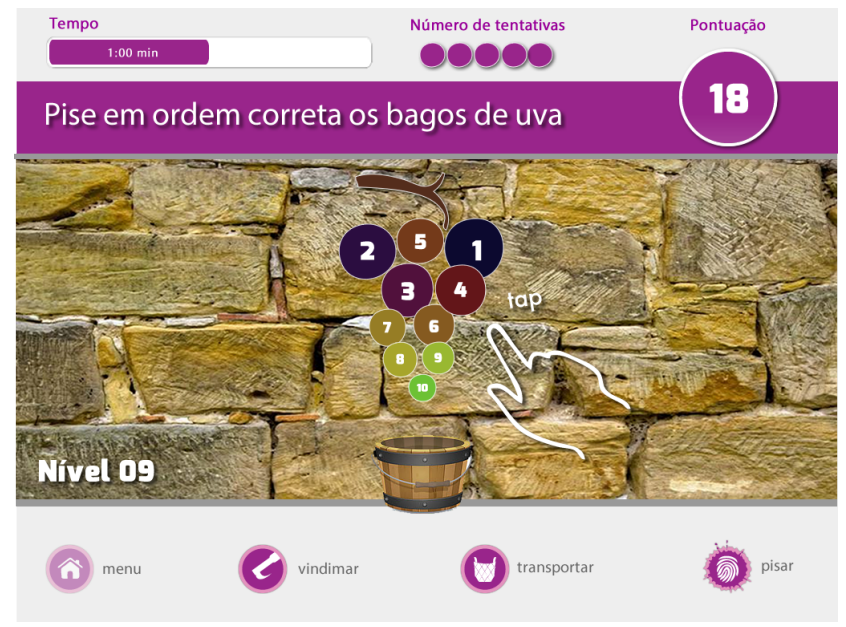

Fig. 4. Game activity proposal for mental exercise of elderly users

This prototype aims to establish activity metrics regarding the amount of interactive areas noticeable by the elderly user, in addition to verify their effectiveness through the use of auditory feedback and visual information.

Prototyping [39] is an efficient and cost-effective way to test design results and to validate the proposed functionality. As this is an iterative process, designs are usually created to identify issues or to validate the user experience. The result of the prototyping process can be the evaluation of design concepts that can further be used to improve proposed designs.

According to Bryer [4], the planning of the game design is one of the main activities that formalize ideas through models that ensure the fun potential that a game can yield. Prototypes are useful in this initial development phase to demonstrate concepts, plans and other mechanical aspects.

Paper prototyping has been chosen for the first development stage of the application. Fullerton [12] argues that low-res prototypes work essentially as sketches whose purpose is to provide a field for testing the mechanics of the game and the operation of certain features. Lewis \& Rieman [23] consider that relevant information can be obtained through the use of paper prototypes. The discussion among the members of the design team can reveal serious aspects and bad performance of the tasks.

The paper prototype adopted at this stage can be classified as of low fidelity as it is of low cost and quick production. It was indispensable for the identification of elements that pervade the mechanics of the game. The following materials were used: a cardboard piece for the composition of the simulated tablet; six A4 sized sheets of paper for the screen and interactive elements and paper overlays mounted on wood sticks to represent the affordances (touch elements).

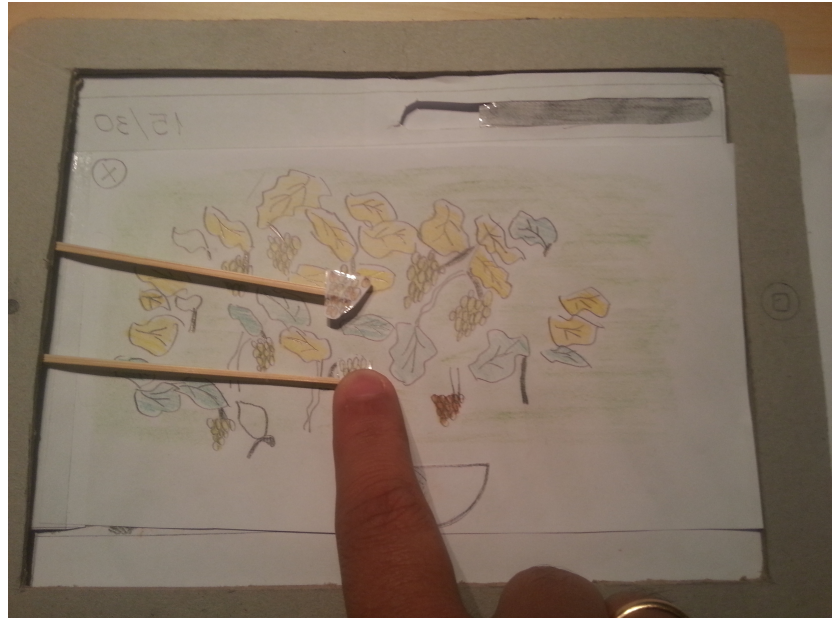

Fig. 5. Paper prototype model with sticks

After the production of the prototypes, it was necessary to test them with users familiarized with interactive game design. The intention in this first testing stage was to explore the conceptual and technical possibilities in terms of components and their arrangements in each screen, to check the effectiveness of the heuristics in realizing the conceptual aspects of the interface, the metaphors and graphical structure, and to seek contributions on the gameplay aspects of the prototype. The contributions of expert users served as basis for the development of a high-fidelity digital prototype for testing with senior users.

This type of contribution, in which developers and experts work together in order to go through a scenario step by step is known as a Design Walkthrough [32] apud Nielsen and Mack (1994). The advantage of these pluralistic routes is a strong focus on users' tasks.

Six users were selected for this test. Nielsen apud Cybis [9] states that at least five evaluators with some level of expertise in interactive systems and interface ergonomics are able to identify about $95 \%$ of software problems, while the same number of novice evaluators can identify $50 \%$ of these problems.

During the initial contact, the individuals were introduced to the nature of the project, and were then free to interact with the prototype, assess, criticize and contribute with suggestions. The evaluation process was done by observation, dialog and recording the issues raised during the walkthrough.

On the first screen, where the user selects the game activities, suggestions addressed naming issues and the positioning of graphic elements. The "collect" icon label, according to two experts, would have more to do with the purpose of the game if their nomenclature reflected more traditional terms such as "harvesting". Similarly the "crushing" label was suggested to be changed to "stomping", this being the usual term for grape maceration.

Still on the main screen, the main question was the senior user ability to interact with the interface and clearer, larger instructional areas were suggested. A way to gain space for 
these changes would be to modify the proposed layout. Some proposed the insertion of a previous screen, with just the logo. This would leave more space on the game activity selection screen.

Another relevant factor was the criticism of the imposed sequentiality of gameplay activities, as the numbering of the icons implied. It was suggested that we removed this constraint, allowing users to choose any activity.

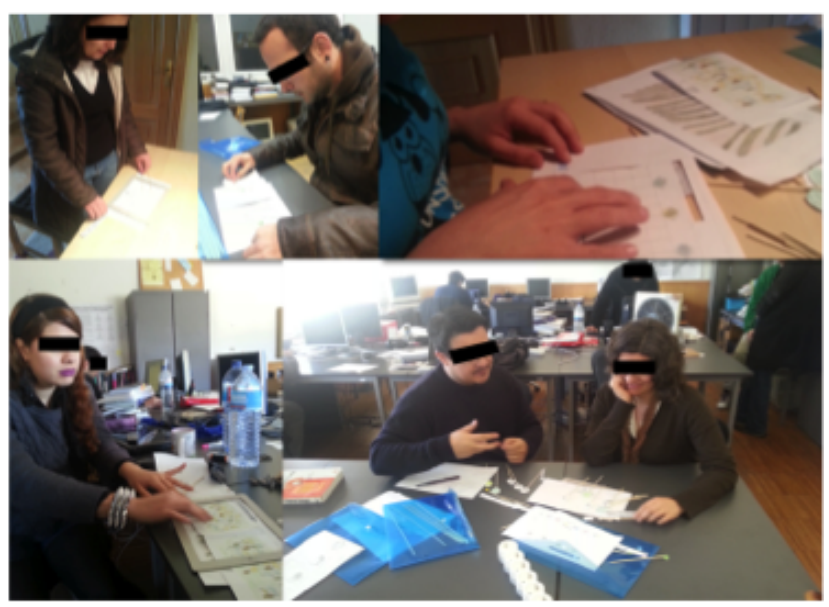

Fig. 6. Design Walkthrough with the experts

The first game activity raised questions about the appearance of interactive affordances and the metaphor underlying this activity. The suggestion was a pop-up that would explain the significance of this stage. The idea of harvesting grapes that were left over or forgotten in the bushes emerged as a justification of the activity.

As this first activity is divided into two parts, clearer instructional areas and the insertion of a tutorial of the game have also been suggested. This division of activities, the insertion of the temporal challenge and the counting of the amount of grape bunches inside the baskets were criticized as factors that can overload the cognitive aspect of the elderly, instigating them to make mistakes. The activity of cutting grape bunches by "flicking" was regarded as interesting. Two alternate options were suggested for this interaction: the insertion of a cutting "tool" (pliers) that would be handled by "dragging", manipulated by the movements of "spreading" and "pinching" and rotated by a "rotating" movement; the other option would be to show the "cutting" order on the cables to separate the bunches from the bushes.

The second activity was criticized because of the static positioning of the wicker baskets. The suggestion was to make the racks more dynamic, to measure the behavior of users and to make the game more challenging. There was a discussion regarding the preview of the trucks before one of these reached the dock: some users would like to know what comes next to try to plan their movements; others consider this a facilitator for the carrying-out of tasks, which would reduce the challenge.
The insertion of "blocked lanes" has been suggested by the individuals assessing the prototype, as this would make the activity of "dragging" more interesting, since fingers flexibility would be exercised.

In relation to the third activity, "stomping" of the grape bunches in the clusters was recommended, since the majority believes that this makes the process more realistic.

Questions about the coloring of the grapes and the order in which they would be crushed were also raised. The insertion of three layers to the challenge was also suggested: crushing could follow a numerical order or be related to colors or dimensions.

\section{HIGH FIDELITY PROTOTYPE}

After the recommendation of specialists and the definition of the concept of the application's interface, it was necessary to develop the high fidelity prototype, in order to perform tests with senior users. In order to do that, we used the Corona SDK, developed by Ansca Mobile.

Using this tool, we were able to insert in the the game aspects related to the positioning and kinetics of the interactive elements, touch movements (flick, touch and drag), duration of activities and score system.

All the elements are set according to the standard resolution of the iPad 2 of $1024 \times 768$. Nevertheless, for licensing related reasons, we chose to develop the application for an ASUS tablet of the same resolution, but runs Android.

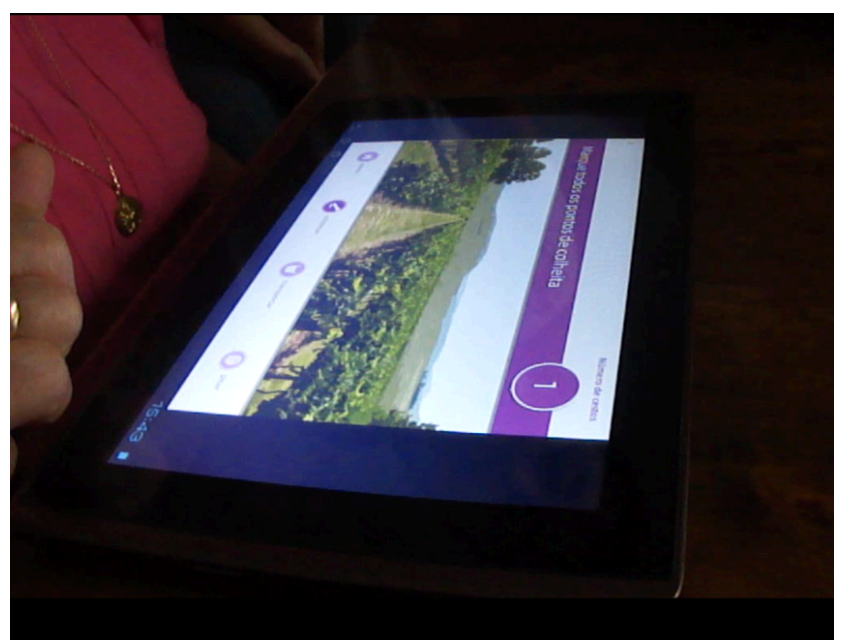

Fig. 7. ASUS Tablet with game prototype

\section{TESTS WITH SENIOR USERS}

Most of the contacted users did not have conditions for moving to the place where the tests would take place. Because of that, we opted for having monitored tests conducted in the field, which led to an approximation to the actual context of 
use. From the evaluator's perspective, tests conducted in the exterior were uncomfortable due to external interference such as excessive brightness from daylight, noise and even presence of other users on the same test environment, which may have caused some interference during the evaluations. Therefore, more than controlled test results we've got results under variable field conditions, which led us to identify other unforeseen relevant aspects.

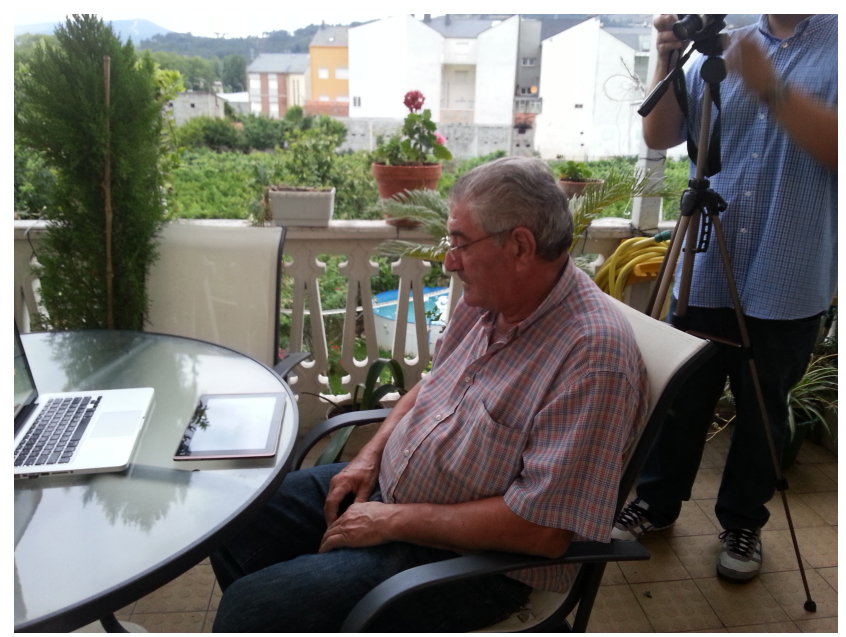

Fig 8 . The test for the application with elderly

We photographed and recorded video to capture the interaction with the tablet and to register facial features during the tasks, in addition to the application of questionnaires before and after the tests. The initial inquiry aimed to identify the profile of the users in this pilot test through the application of a questionnaire with 12 seniors.

This pilot population included seniors with age above 60 , with both genders well represented and many diagnosed with non-completely impairing conditions. With the necessary equipment for documentation and users informed about the process, we conducted this pilot study. Scripts were established for the tasks with the prototype:

1. Interacting with the first activity of the prototype. This consisted of a) identifying each of the green dots (affordances) on screen and b) switching to sub-activity 1 and "cutting" the grapes. The intention was to calibrate two heuristics: a) appropriate sizing and spacing and $b$ ) consistency of interfaces and visual acuity. In this activity we evaluated the assertiveness, error ratio and the drive time in relation to targets, regarding scaling and chromatic effects.

2. Interacting with the second activity of the prototype.

This activity consisted on taking each of the four baskets to the truck of the corresponding color. The heuristic evaluated at this stage was the graphic and interactive consistency. It was taken in consideration the amount of mistakes and successes before there were changes of placement, and the coloring of interactive elements of the game.

\section{Interacting with the third prototype activity.}

This last activity intended to calibrate the following heuristics: a) the amount of affordances/points of interaction and b) bimodal feedback. The chosen task to exercise those was the sequential crushing of grapes. The evaluation was done by counting the mistakes, successes and response times during the simultaneous appearance of targets, with and without the use of auditory feedback.

For this evaluation phase, two actions were proposed: the analysis of actions and behaviors of the elderly by looking at interaction $\operatorname{logs}$ and records of the emotions of the users through video recording and task satisfaction surveys. The interpretation of interaction logs was based on the Goal Question Metric (GQM) paradigm, which focuses on an approach based on an effective measure introduced by Victor Basili at the University of Maryland [2]. This evaluation model is divided in three levels, which are:

a) GOAL - in which intentions were synthesized as goals to be achieved in a context. The measurement of goals involves products, processes and resources. For this project, the following goals were established:

a1) To check the assertiveness of users in respect of affordances by size and by alpha level;

a2) To check the assertiveness of users in respect of affordances by presence or not of aural component;

a3) To identify whether there was variable size accuracy, on the cutting of the cable of the grapes;

a4) To identify what the relationship between assertiveness and standardization of positioning of elements is;

a5) To identify the assertiveness of users according to the quantity of targets and auditory feedback;

a6) To identify if there was improvement of performance through the use of bimodal feedback.

b) QUESTIONS - in which the questions to be answered were established in order to allow decision-making in relation to the proposed objectives. In this project the following questions were formulated:

b1) How many affordances were most accessed by users?

b2) How many affordances were not perceived by users (weren't clicked)?

b3) What was the average time of the user response after the appearance of each affordance?

b4) What was the average time of each cable cutting?

b5) How many errors (baskets turned) happened in each game level?

b6) What was the average time players spent on each level?

b7) How many levels were overcome with and without the presence of the bimodal affordance?

b8) What was the minimum number of simultaneous berries that lead to user error?

b9) What was the average user response by use of unimodal or bimodal feedback?

c) METRICS- in which the processing of quantitative indicators was enabled, from which answers to the questions proposed will be formulated. The following points were established as metrics for the evaluation of the prototype: 
c1) Comparison of the number of affordances most accessed by users;

c2) Comparison of the quantity of affordances of different sizes and alphas in the presence or absence of sound;

c3) Amount of affordances not perceived by users;

c4) Average time to trigger the unimodal (visuals) and bimodal (visual and auditory) affordances

c5) Average time of cutting cables:

c6) Amount of basket collision errors in relation to change of target placement;

c7) Average time of permanence of the player at each level;

c8) Number of levels overcome with or without the presence of bimodal affordances;

c9) Number of simultaneous berries that lead to user error;

c10) Average user response time with unimodal or bimodal feedback.

Capturing interaction logs extracted from the prototype was relevant to obtain data related to size, spacing and movement pertinent to at least five calibration heuristic proposals. One of the heuristics, however, relates to the use of metaphors. In that case, quantitative data is not the most appropriate for this research, since issues related to human emotions are being assessed. A conversational think-aloud method was used as an alternate strategy for obtaining qualitative data. Another important action was the behavioral assessment of users from a set of 10 emotional heuristics [8] to identify the reactions of the elderly during game play.

This analysis was performed by the observation of videos of users interacting with the prototype; a paper register guided the occurrence of emotions. At the end of the interactions, users answered a few questions about the prototype, which covered the perceived level of difficulty of the proposed tasks, in addition to issues related to the understanding of the vindima metaphor.

\section{CONCLUSION AND FUTURE STUDIES}

This article has shown the preliminary steps of a study on the access of multitouch devices for elderly people, from designing the concept of the interface to the preparation of tests with users. The research started from the hypothesis that there is a fine line that separates a good possibility of use from info exclusion. This project was divided in two parts: proposal of heuristics, a step that has already been achieved, and their validation through a game prototype.

One of the challenges of the first stage was the extensive state-of-the- art collection related to guidelines, because much of the work reviewed was based on adaptations of heuristics for the web.

The proposition of new guidelines for touch technologies directed to the elderly has made research challenging. All of the six proposed heuristics try to contemplate cognitive, sensory and motor exercise. The intention is that all are assessed through the prototype - which will calibrate positioning and sizing aspects of affordances, feedback quality, interface metaphors and gestures patterns and readability of graphical elements.

More than just a tool for verifying the heuristics, the intention behind the game design had in consideration the cultural aspects of the elderly's daily life, so that they would not feel taunted during the interaction. The insertion of the grape harvesting context, a popular and family festivity, highlights the concern with the appropriate metaphors.

At the end of the validation tests, it is hoped that this research contributes for other related studies and serve as a reference for the development of multitouch applications that suit the needs of the elderly, empowering them to make use of these in the improvement of their quality of life and in their inclusion in society.

\section{REFERENCES}

[1] Agner, Luiz. 2006. Ergodesign e Arquitetura de Informação: Trabalhando com o usuário. 1 Ed Rio de Janeiro: Quartet.

[2] Basili, V., Caldeira, C. and H. D. Rombach, "Goal Question Metric Paradigm," in J. Marciniak (ed.), Encyclopedia of Software Engineering, John Wiley and Sons, 1994, pp. 528-532.

[3] Bhalla, A.V. (2010). Comparative Study of Various Touchscreen Technologies. International Journal of Computer Applications, Vol.6, No.8, pp. 12-18, ISSN 09758887,2010.

[4] Bryer, F. B., Credidio, D., Neves, A., 2007. Prototipagem rápida para avaliação de game design. In: VI Simpósio Brasileiro de Jogos para Computador e Entretenimento Digital. São Leopoldo. Anais do VI Simpósio Brasileiro de Jogos para Computador e Entretenimento Digital, 2007.

[5] C. Rusu, S. Roncagliolo,V. Rusu and C. Collazos. A Methodology to establish usability heuristics.ACHI, pages 59-62, 2011.

[6] Caprani, Noel E. O'Connor and Cathal Gurrin. Touch Screens for the Older User, Assistive Technologies, Dr. Fernando Auat Cheein (Ed.), ISBN: 978-951-0348-6, InTech, Disponível em: http://www.intechopen.com/books/assistive-technologies/touch- screensfor-the-older-user,2012.

[7] Censos 2011. Resultados provisórios. Instituto Nacional de Estatística .I.P. Lisboa, Portugal. ISBN 978-989-25-0148-2

[8] Chen, Yan, et al. "The Experimental Approaches of Assessing the Consistency of User Interface." Human-Computer Interaction. Interaction Design and Usability: 12th International Conference, HCI International 2007, Beijing, China, July 22-27, 2007, Proceedings. Springer-Verlag Berlin Heidelberg, 2007.

[9] Cybis, Walter. Ergonomia e Usabilidade: conhecimentos, métodos e aplicações. São Paulo: Novatec Editora, 2007.

[10] Filho, João Gomes. Ergonomia do Objeto. Escrituras Editora, 2003.

[11] Flurry Analytics. The smartphone or the tablet: Who's using all these devices? Acesso: Fevereiro de 2013, disponível: http://news.cnet.com/8301-1023_3-57542081-93/the-smartphone-or-thetablet-whos-using-all-these-devices/

[12] Fullerton, T., 2008. Game Design Workshop: A Playcentric Approach to Creating Innovative Games, 2nd Edition. Morgan Kaufmann, February 2008.

[13] Garret, Jesse.The Elements of User Experience: User-Centered Design for the Web and Beyond. New Riders- Berkeley.2011. 
[14] Grandjean, Etienne. Manual de ergonomia: adaptando o trabalho ao homem / Etienne Grandjean; trad. João Pedro Stein. - Porto Alegre: Artes Médicas, 1998.

[15] Hevner "Design Science in Information Systems Research", MIS Quarterly, 2004

[16] IBGE - Instituto Brasileiro de Geografia e Estatística. Departamento de população e indicadores sociais. Perfil dos idosos responsáveis por domicílios no Brasil. Rio de Janeiro. 2010. Disponível em $<$ http://www.ibge.gov.br/>. Acesso em: 10 ago 2012.

[17] Ingram,A.,Wang,X.,and Ribarsky,W.Towards the establishment of a framework for intuitive multi-touch interaction design. In Proceedings of the international Working Conference on Advanced Visual interfaces http://doi.acm.org/10.1145/2254556.22545 71,2012.

[18] Iida, Itiro. Projeto e produção. 2a ed. São Paulo: Edgard Blucher, 2005.

[19] Jacko, J.A., Scott, I. U., Sainfort, F., Moloney, K. P., Kongnakorn,T., Zorich, B. S., and Emery,V. K. Effects of multimodal feedback on the performance of older adults with normal and impaired vision. In Proceedings of the User interfaces For All 7th international Conference on Universal Access: theoretical Perspectives, Practice, and Experience (Paris, France, October 24 - 25, 2002). N. Carbonell and C. Stephanidis, Eds. Springer-Verlag,Berlin,Heidelberg,3-22.2003

[20] Jin, Z., Plocher,T., \& Kiff, L.Touch screen user interfaces for older adults: Button size and spacing. In C. Stephanidis (Ed.), Universal access in human computer interaction. Coping with diversity (pp. 933941). Berlin, Germany: Springer.2007

[21] Kachar,Vitória.Terceira idade e informática: aprender revelando potencialidades. São Paulo: Cortez, 2003.

[22] Lera, E. and Domingo, M. G.Ten Emotion Heuristics: Guidelines for assessing the user's affective dimension easily and cost-effectively. In BCS-HCI ' 07 Proceedings of the 21st British HCI Group Annual Conference on People and Computers: HCI... but not as we know it, 2, Publisher British Computer Society Swinton, (2007), 163-166.

[23] Lewis, C. Rieman, J., 1994. Task-Centered User Interface Design: A Practical Introduction. Disponível em: www.hcibib.org/tcuid [Último acesso em: 08/08/2011].

[24] Moggridge, B. Designing Interactions.The MIT Press.2006

[25] Norman,A. Donald.The design of everyday things. NewYork: Basic Books, 1989.

[26] Norman and Jakob Nielsen. Gestural interfaces: a step backward in usability. Interactions 17, 5 (September 2010), 46-49. DOI= http:// doi.acm.org/10.1145/1836216.1836228,2010.

[27] Organización Mundial de La Salud. Envejecimiento y ciclo de vida. Website.Disponível: http://www.who.int/features/factfiles/ageing/es/index.html. 2011

[28] Papaléo Neto, Matheus. Gerontologia: a velhice e o envelhecimento em visão globalizada. São Paulo: Editora Atheneu, 2000.

[29] Pak and A. Mclaughlin.Designing Displays for older adults. CRC Press - Taylor \& Francis Group.2011.

[30] Pinto.Contributos da psicologia para o estudo de rotinas, tradições, celebrações e rituais familiares. Comunicação \& Cultura, n. ${ }^{\circ}$ 10, 2010.
Disponível em: http://comunicacaoecultura.com.pt/wpcontent/uploads/04.-H.R.Pinto-M.T.Ribeiro.pdf

[31] Phiriyapokanon,Tanid. Is a big button interface enough for elderly users?:Towards user interface guidelines for elderly users. Mälardalens högskola, Akademin för innovation, design och teknik. Disponível em: http://urn.kb.se/resolve?urn=urn:nbn:se:mdh:di va-12247.2011.

[32] Preece, Jeniffer. Design de Interação: além da interação homemcomputador. Porto Alegre: Bookman, 2005.

[33] Saffer, D. Designing Gestural Interfaces:Touchscreens and Interactive Devices. O’Reilly Media, Inc. 2008

[34] Silva.Fernando. Investigar em design vs investigar pela prática do design- um novo desafio científico. INGEPRO - Inovação, Gestão e Produção. ISSN 1984-6193. vol. 02, no. 04.2010.

[35] Stoessel, C.,Wandke, H., and Blessing, L. Gestural interfaces for elderly users: help or hindrance?. In Proceedings of the 8th international Conference on Gesture in Embodied Communication and HumanComputer interaction (Bielefeld, Germany, February 25 - 27, 2009). S. Kopp and I.Wachsmuth, Eds. Springer-Verlag, Berlin, Heidelberg, 269280. DOI= http://dx.doi.org/10.1007/978-3-642-12553-9 24.2010.

[36] Sun, X., Plocher,T., and Qu,W.An empirical study on the smallest comfortable button/ icon size on touch screen. In Proceedings of the 2 nd international Conference on Usability and internationalization (Beijing, China, July 22 - 27, 2007). N. Aykin, Ed. SpringerVerlag,Berlin,Heidelberg,615-621.2007

[37] Tanaka, Misami. A HDTV e a Televisão Digital no Japão: As primeiras tendências e as primeiras experiências. Revista do NP em Comunicação Audiovisual da Intercom, São Paulo, v.1, n.1, p. 229-239 jan./jun. 2008 Yang, Tyler. Appropriate User Interface for the Elderly.

[38] Umemuro, H. Lowering Elderly Japanese Users' Resistance towards Computers by Using Touchscreen Technology. Universal Access in the Information Society,Vol.3, No.3, (July 2004), pp. 276-288.2004Wigdor, Daniel, and Dennis Wixon. Brave NUI world: designing natural user interfaces for touch and gesture. Morgan Kaufmann, 2011.

[39] Unger, R., Chandler, C. (2009). A Project Guide to UX Design: For User Experience Designers in the Field or in the Making, Capítulo 11, New Riders

[40] Yang, Tyler. Appropriate User Interface for the Elderly.

[41] Yousef, M. K. Assessment of metaphor efficacy in user interfaces for the elderly: a tentative model for enhancing accessibility. In Proceedings of the 2001 EC/NSF Workshop on Universal Accessibility of Ubiquitous Computing: Providing For the Elderly (Alcácer do Sal, Portugal, May 22 - 25, 2001). WUAUC'01. ACM, NewYork, NY, 120-124. DOI= http://doi.acm.org/10.1145/564526.564557. 2001.

[42] Wigdor, Daniel, and Dennis Wixon. Brave NUI world: designing natural user interfaces for touch and gesture. Morgan Kaufmann, 2011. 